\title{
Primer-mediated Enzymatic Amplification of Cytomegalovirus (CMV) DNA Application to the Early Diagnosis of CMV Infection in Marrow Transplant Recipients
}

Sharon A. Cassol, Man-Chiu Poon, Rajinderpal Pal, Margaret J. Naylor, Jeremy Culver-James, Thomas J. Bowen, James A. Russell, Stephen A. Krawetz, Richard T. Pon, and David I. Hoar

The Canadian Red Cross, Blood Transfusion Service, Calgary, Alberta, Canada T2R 1J1; and the Departments of Medical Biochemistry, Pediatrics, and Medicine, the University of Calgary, Calgary, Alberta, Canada T2N 4N1

\begin{abstract}
A nucleic acid amplification procedure, the polymerase chain reaction (PCR), has been used to establish a diagnostic assay for the identification of cytomegalovirus (CMV) immediateearly sequences in clinical specimens. Preliminary testing against virus-infected cell cultures indicated that the PCR assay was highly CMV-specific, recognizing both wild-type and laboratory strains of CMV. There was no cross-reactivity with human DNA or with DNA from other herpes viruses. The sensitivity of the assay, using cloned CMV AD169 Eco RI fragment-J as template, was 1 viral genome per 40,000 cells. In a prospective study of CMV infection in bone marrow transplant recipients, the PCR assay correctly identified four patients with confirmed CMV infection. In three of these patients who were followed longitudinally, correlation of DNA reactivity with CMV culture and CMV antibody status over time indicated that DNA was the most sensitive marker for the diagnosis of CMV infection.
\end{abstract}

\section{Introduction}

Cytomegalovirus (CMV) ${ }^{1}$ infections are a major cause of illness and death in immunocompromised patients $(1,2)$. As many as $25 \%$ of allogeneic bone marrow transplant (BMT) recipients die of disseminated CMV disease with interstitial pneumonitis (IP) (3). Rapid diagnosis and early treatment form the basis for the effective clinical management of these patients.

Currently most diagnoses depend on a rise in anti-CMV antibody titer or on the direct isolation of CMV from infected tissues. Neither procedure is satisfactory. Antibody responses are often delayed or completely absent in immunosuppressed marrow recipients (4) and recovery of CMV in culture can take up to 6 wk to obtain a definitive result (5).

Address reprint requests to Dr. S. Cassol, The Canadian Red Cross, Blood Transfusion Service, 737 13th Avenue, S.W., Calgary, Alberta, Canada T2R $1 \mathrm{~J} 1$.

Received for publication 12 February 1988 and in revised form 23 September 1988.

1. Abbreviations used in this paper: BMT, bone marrow transplant; CMV, cytomegalovirus; HSV, herpes simplex virus; IE, immediateearly; IP, interstitial pneumonitis; PCR, polymerase chain reaction; VZV, varicella zoster virus.

J. Clin. Invest.

(c) The American Society for Clinical Investigation, Inc.

0021-9738/89/04/1109/07 \$2.00

Volume 83, April 1989, 1109-1115
Recently it has been shown that the rapidity of CMV diagnosis can be increased using either MAb to demonstrate the presence of viral antigens (6) or DNA probes to detect viral nucleic acid (7-9). The major drawbacks of these technologies have been their lack of sensitivity when compared with conventional culture methods $(10,11)$ and, in the case of DNA, the frequent hybridization of probes with bacterial sequences found in nonsterile specimens $(12,13)$.

To circumvent these problems and facilitate the diagnosis of CMV disease, we have used an in vitro gene amplification technique to increase both the sensitivity and specificity of CMV DNA detection. The technique, known as the polymerase chain reaction (PCR), uses synthetic oligonucleotide primers and DNA polymerase to enzymatically amplify selected DNA target sequences, up to several million-fold in $2 \mathrm{~h}$ (14). PCR amplification has been successfully applied to the diagnosis of sickle cell anemia (15), hemophilia (16), human papilloma virus (17), HIV-1 $(18,19)$, and the human T cell lymphoma/leukemia virus (20). We report the adaptation of PCR technology to the identification of CMV DNA in blood, urine, saliva, and lung tissue and we describe our preliminary experience using this technology to longitudinally monitor CMV infections in BMT recipients. To evaluate the efficacy of PCR testing we have correlated CMV DNA patterns over time with clinical outcome and with CMV serology and the ability to isolate CMV in culture.

\section{Methods}

Patients and specimen collection. Seven allogeneic BMT recipients receiving their transplants at the Foothills Hospital, Calgary, AB, were longitudinally sampled pretransplant and on several occasions (up to 10 times) posttransplant. An eighth BMT recipient, a patient at the Montreal General Hospital, was sampled on two occasions only. Serum was collected for antibody studies; urine, saliva, and blood for CMV DNA studies. An aliquot of each specimen was sent to the Provincial Laboratory at Foothills Hospital for viral culture. Allograft donors were similarly sampled at the time of transplantation. Controls consisted of 10 healthy apheresis donors sampled serially (every $3 \mathrm{mo}$ ) over an 18-mo period.

Viral and control DNA. Cloned Eco RI fragment-J (10.6 kb) containing the complete DNA sequence coding for the major immediateearly (IE) gene of CMV strain AD169 was provided by Dr. B. Fleckenstein, Universität Erlangen-Nürenberg, Erlangen, FRG (21). CMV AD169 (VR-538) and Davis (VR-807) were obtained from the American Type Culture Collection in Rockville, MD, as were herpes simplex virus type I (HSV-I) strain F (VR-733), HSV-II strains G (VR-734) and MS (VR-540), and varicella zoster virus (VZV) strains Oka (VR-795), Webster (VR-916), and Ellen (VR-586). EBV was the gift of Dr. J. Roder, Mount Sinai Medical Research Institute, Toronto, Ont., and purified HSV-I total virion DNA was obtained from Dr. R. Chan, University of Toronto, Toronto, Ont. Wild-type strains of herpes viruses including eight isolates of CMV, six of VZV, and three each of 


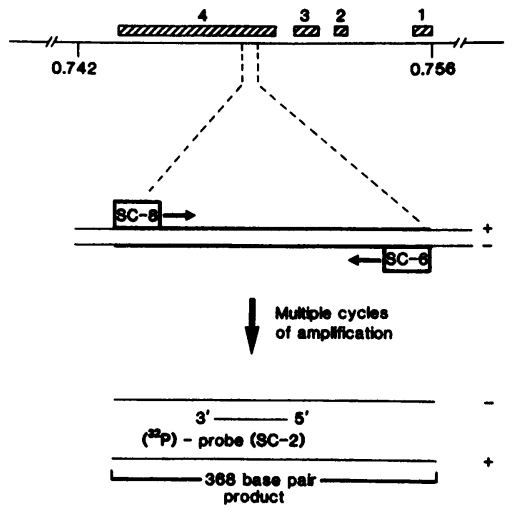
mentary to the $(-)$ and $(+)$ strands, respectively. The arrows indicate the direction of primer extension. The primers are positioned so that the enzyme-catalyzed, template-directed extension product of one primer serves as the template for the other. Repeated cycles of denaturation, primer annealing, and extension result in the accumulation of a 368-bp CMV-specific amplification product that is defined by the distance between the $5^{\prime}$ ends of the two primers. (Bottom) The amplification product and its relationship to the probe, SC-2. The probe is 30 bases long and is complementary to the (-) strand of the amplified product, but not to the primers.

HSV-I and HSV-II were provided by the Alberta Provincial Laboratory. The presence of CMV in wild-type strains was confirmed by indirect immunofluorescence using an MAb against the 72,000-D early nuclear protein (11).

Isolation of DNA. The methods used for DNA extraction from virus-infected cell cultures, whole blood, PMN- and mononuclearenriched blood fractions have been described previously $(22,23)$. For studies of CMV excretion, $12 \mathrm{ml}$ of urine or saliva (collected in saline) were centrifuged for $1 \mathrm{~h}$ at $38,000 \mathrm{rpm}(180,000 \mathrm{~g})$ in an $S W-41$ rotor in a centrifuge (Beckman Instruments, Inc., Palo Alto, CA). The concentrated viral pellets were then lysed and DNA was extracted (22). $10-\mu l$ aliquots of each DNA extract (equivalent to $3.0 \mathrm{ml}$ of the original fluid) were amplified as described below.

Selection and preparation of DNA primers and probe. For PCR studies, we chose to amplify a 368-bp segment of the fourth exon of the major CMV IE gene. This region of the genome was selected since it is highly conserved between CMV strains $(24,25)$ and it has no reported homology with human DNA $(26,27)$. Synthesis of the primers and probe were performed on a DNA synthesizer (model 380 A; Applied Biosystems, Foster City, CA) using published sequence data (24) and the methoxyphosphoramidite method (28). The design of the PCR procedure for detection of CMV IE sequences is outlined in Fig. 1.

Sequence amplification with DNA polymerase. Amplification reactions were performed according to the procedure of Kogan et al. (16). 1 $\mu \mathrm{g}$ samples of DNA (or $10 \mu \mathrm{l}$ of urine/saliva) were routinely amplified for 40 cycles using $1.0 \mathrm{U}$ of Taq DNA polymerase (Perkin ElmerCetus, Rexdale, Ont.) and reaction times of $2 \mathrm{~min}$ at $50^{\circ} \mathrm{C}$ for annealing, $3 \mathrm{~min}$ at $70^{\circ} \mathrm{C}$ for extension, and $1 \mathrm{~min}$ at $85^{\circ} \mathrm{C}$ for denaturation. In some experiments, crude cell lysates (representing $0.2 \times 10^{6}$ cells) were amplified directly without the use of DNA extraction. Lysates were prepared by heating cell suspensions to $95^{\circ} \mathrm{C}$ for $5 \mathrm{~min}$. DNA specimens from individual patients (or donors) were analyzed in groups, each of which represented a serial collection obtained over a period of months. As a control on internal consistency, four reference standards were included in each PCR reaction. These standards were prepared by seeding 1- $\mu$ g quantities of uninfected human Wi 38 fibroblast DNA with known amounts of CMV AD169 Eco RI fragment-J ranging from $2.86 \times 10^{-10}$ to $1.43 \times 10^{-7} \mathrm{pmol}$.

Southern analysis of amplification products. Amplified sequences were detected by Southern transfer and hybridization with [ $\left.{ }^{32} \mathrm{P}\right] \mathrm{SC}-2$, a 30-base long synthetic probe (Fig. 1). Aliquots of each amplification reaction (usually one-tenth of the final volume) were electrophoretically separated in $2.0 \%$ agarose gels and transferred by alkaline blot method (29) onto Zeta-Probe (Bio-Rad Laboratories, Mississauga, Ont.) nylon membranes. After neutralization the filters were individually prehybridized at $42^{\circ} \mathrm{C}$ for $2 \mathrm{~h}$ in $10 \mathrm{ml}$ of $0.5 \mathrm{M}$ sodium phosphate buffer (355 mg NaHPO $, 0.2 \mathrm{ml} \mathrm{85 \%} \mathrm{H}_{3} \mathrm{PO}_{4} / 10 \mathrm{ml}, \mathrm{pH}$ 7.2) containing $0.1 \mathrm{M} \mathrm{NaCl}, 1 \% \mathrm{BSA}, 2 \% \mathrm{SDS}, 30 \%$ formamide, $1.0 \mu \mathrm{M}$ EDTA, and $0.4 \mathrm{mg} / \mathrm{ml}$ yeast RNA. Hybridization with $8 \mathrm{ng} / \mathrm{ml}$ of $\left[{ }^{32} \mathrm{P}\right] \mathrm{SC}-2$ probe in $10 \mathrm{ml}$ of the same solution was carried out for $3 \mathrm{~h}$ at $42^{\circ} \mathrm{C}$. The probe was phosphorylated at its $5^{\prime}$ terminus to a specific activity of between 6 and $8 \times 10^{8} \mathrm{cpm} / \mu \mathrm{g}$ using [gamma- ${ }^{32} \mathrm{P}$ ]dATP and T4 polynucleotide kinase (30). Filters were washed three times at room temperature and once at $42^{\circ} \mathrm{C}$ for $15 \mathrm{~min}$ each in $0.75 \mathrm{M} \mathrm{NaCl}, 0.075 \mathrm{M}$ sodium citrate, and $0.1 \%$ SDS, $\mathrm{pH} 7.2$. Autoradiography was routinely performed for $18 \mathrm{~h}$ at $-70^{\circ} \mathrm{C}$ using X-Omat AR film (Eastman Kodak Co., Rochester, NY) and a single intensifying screen (Lightning Plus; Dupont Instruments, Mississauga, Ont.).

Antibody studies. IgG and IgM antibodies to CMV were determined separately using a solid-phase enzyme immunoassay, Enzygnost anti-CMV (Behring Diagnostic, Montreal, Que.). For IgM analysis, test samples were pretreated with RF Absorbent (Behring Diagnostic) to remove rheumatoid factor. Serum samples from individual patients and donors were batched and analyzed simultaneously in a single assay.

\section{Results}

Sensitivity and specificity of CMV PCR testing. In preliminary amplification studies, purified CMV AD169 Eco RI fragment-J was used as the IE gene template. The product of amplification was an SC-2 hybridizing fragment that migrated at the position expected of an amplified 368-bp target sequence (Fig. $2 \mathrm{~B}$ ). When $1.43 \times 10^{-7} \mathrm{pmol}$ of Eco RI fragment-J was amplified in the presence of $1 \mu \mathrm{g}$ of Wi 38 fibroblast DNA, the efficiency of the reaction, calculated by the method of Saiki et al. (14), was $75 \%$. No hybridization signal was detected with unamplified DNA or with uninfected Wi 38 fibroblast DNA.

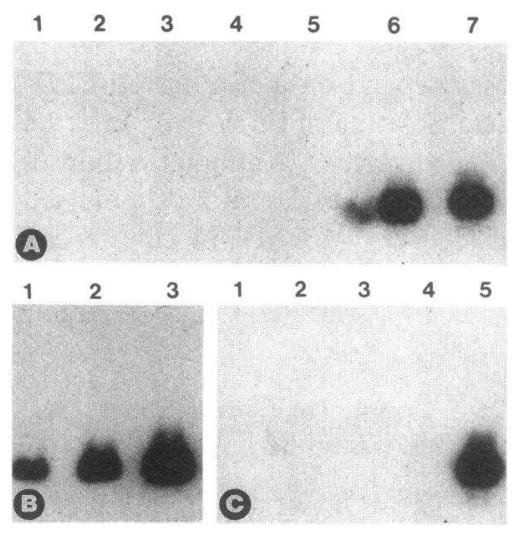

Figure 2. Autoradiographs showing Southern analysis of viral and control DNA amplified by the CMV PCR procedure (18-h exposure). (A) Amplification (40 cycles) of whole cell lysates infected with HSV-I strain F (lane 1), HSV-II strain MS (lane 2), VZV strains Oka, Webster, and Ellen (lanes 3, 4, and 5, respectively), and CMV wild-type strains isolated from clinical specimens (lanes 6 and 7). Only CMV-infected samples yielded a positive hybridization signal. (B) Amplification of the cloned IE sequence, CMV AD169 Eco RI fragment-J (400 pg). The intensity of the hybrization signal increased with increasing numbers of PCR cycles. Lane 1, 15 cycles; lane 2, 20 cycles; lane 3, 25 cycles. ( $C$ ) Amplification (40 cycles) of DNA extracted from urine (lane 1), saliva (lane 2), whole blood (lane 3), and PMN-enriched peripheral blood cells (lane 4) of an asymptomatic CMV seronegative blood donor (negative control). Lane 5 contains 1 pg of Eco RI fragment-J (positive control). 
To estimate the sensitivity attainable with CMV PCR amplification, Wi 38 fibroblast DNA was spiked with serial dilutions of Eco RI fragment-J and amplified for 40 cycles. Onetenth of each amplification reaction was then analyzed by Southern transfer hybridization with $\left.{ }^{32} \mathrm{P}\right] \mathrm{SC}-2$. Using this reconstruction system, as little as $0.0001 \mathrm{pg}\left(0.143 \times 10^{-10} \mathrm{pmol}\right.$, 8.6 molecules) of the CMV IE gene was readily detectable in 2 $\mu \mathrm{g}$ of cellular DNA ( 320,000 cells) to give a sensitivity (after 18 $h$ of autoradiographic exposure) of 1 viral genome per 40,500 cells. As outlined in Methods, a selection of these reconstituted specimens was included in each PCR reaction as a measure of intertest variability. Our results showed little or no variation between runs. We consistently detected at least one viral genome per 20,000 cells.

Specificity studies were performed on established cell lines (ATCC) harboring known strains of CMV (AD169, Davis), HSV-I (F), HSV-II (G and MS), and VZV (Oka, Webster, and Ellen). Additional controls included DNA extracted from EBV-infected B95-8 marmoset cells, as well as $100 \mathrm{pg}$ each of purified HSV virion DNA, pBR322 DNA and Escherichia coli DNA. The high degree of specificity contributed by the PCR amplification procedure was shown by the complete lack of any hybridization signal with amplified HSV, EBV, VZV, pBR322, or E. coli DNAs. Representative results are shown in Fig. $2 A$, lanes $1-5$. In contrast, strong positive hybridization signals were obtained by the amplification of both Davis and AD169 strains of CMV (Fig. 3 B, lanes 8 and 9). Retesting of the same samples gave identical results; negatives were consistently negative and positives were consistently positive.

CMV PCR testing of wild-type strains. Before using PCR for diagnosis, it was necessary to establish whether the assay could identify wild-type strains of CMV found in clinical specimens. Eight clinical strains, grown from the urines of different patients, were passaged in human fibroblast cell lines. DNA was extracted and amplified as described. In some studies the infected cells were lysed and analyzed by direct amplification without previous DNA extraction. All eight clinical strains of CMV gave reproducible hybridization signals corresponding to the CMV-specific IE gene amplification product. Fig. $2 \mathrm{~A}$ shows representative results for two of these isolates (lanes 6 and 7). Wild-type HSV and VZV, on the other hand, failed to give any detectable hybridization signals in three different PCR runs.

Direct CMV PCR testing of clinical specimens: correlations with clinical disease. A total of 504 specimens were analyzed by CMV PCR: 154 from BMT patients and 350 from healthy asymptomatic blood donors. The results of PCR testing are shown in Table I. Again, many of these samples (both positive and negative) were retested and identical results were obtained.

The incidence of DNA positivity in the BMT population was highest in patients with disseminated CMV disease with IP (78\%), intermediate in patients with mild or subclinical CMV infection (64 and 31\%), and lowest in BMT patients with no evidence of CMV infection (0\%). The strongest hybridization signals were observed with lung samples from two patients with IP (Fig. $3 A$, lanes 2 and 3; Fig. $3 B$, lane 1).

Lesser amounts of CMV DNA were detected in two of three asymptomatic CMV seropositive blood donors. One donor was positive for saliva on one occasion only. The second was positive twice for both saliva and the PMN-enriched cell fraction of peripheral blood. 12 of $13 \mathrm{CMV}$ seronegative

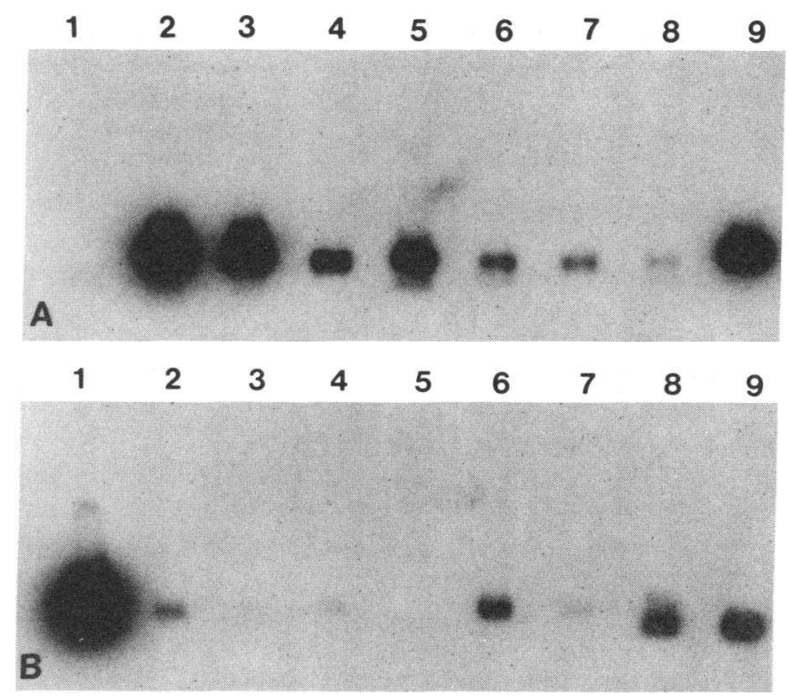

Figure 3. Autoradiographs showing results of PCR amplification for the diagnosis of CMV infection in BMT patients (18-h exposure). $(A)$ Representative PCR results for BMT patient 1 . Lane 1 contains peripheral blood DNA extracted from the BMT donor at the time of transplantation. The donor was CMV seronegative and CMV DNA negative. Lanes 2-5 contain DNA isolated from the BMT recipient at 8 wk posttransplant when IP was first suspected. Bronchial washes from the right and left lung (lanes 2 and 3, respectively) were strongly CMV DNA positive. Urine (lane 5) and whole blood (not shown) were also CMV DNA positive. In blood, the DNA was concentrated in the PMN-enriched cell fraction (lane 4). Viral cultures at this time were still negative. Lanes 6-8 contain whole blood DNA isolated from the BMT recipient at 24,32 , and $48 \mathrm{wk}$ posttransplant when the levels of CMV DNA in blood were gradually waning. Lane 9 contains urine at 60 wk posttransplant. $(B)$ Representative PCR results for BMT patients 3 and 4. DNA was extracted and analyzed by PCR and Southern hybridization as described above. Patient 4 was sampled twice at the time of acute IP. Lung biopsy tissue was strongly CMV DNA positive (lane 1). Urine was weakly DNA positive (lane 4). In peripheral blood, CMV DNA was detected in the PMN-enriched cell fraction (lane 2) but not in the mononuclearenriched fraction (lane 3). Specimens from patient 3 were collected serially over $33 \mathrm{wk}$. Lane 5 contains whole blood DNA at the time of transplant when the patient was CMV seronegative and CMV DNA negative. At 11 wk posttransplant peripheral blood became CMV DNA positive for the first time (lane 6). By 17 wk the patient had seroconverted to IgM positivity and CMV DNA was detectable in urine (lane 7). Lanes 8 and 9 contain amplified DNA from cell cultures infected with CMV strains AD169 and Davis, respectively (positive controls).

donors tested completely negative for CMV DNA. The 13th tested positive on two occasions for both urine and saliva.

Patterns of CMV reactivity in individual BMT patients. Of particular interest were three patients who became CMV DNA positive before isolation of infectious virus in culture (patients 1 and 2) and before seroconversion (patient 3). A fourth patient with CMV infection was not studied longitudinally.

Patient 1 (Figs. $3 A$ and 4) was a 23-yr-old woman with acute lymphoblastic leukemia in remission. She was transplanted from her male sibling (partially mismatched in HLADR and C loci) in May 1985. The patient was IgG CMV antibody positive (IgM antibody negative) pretransplant. Her BMT donor was CMV seronegative. Acute graft vs. host disease developed $8 \mathrm{~d}$ post-BMT and was treated with steroids 
Table I. Correlation of Hybridization Results with Clinical Status in Seropositive and Seronegative Persons

\begin{tabular}{|c|c|c|c|c|c|c|c|}
\hline \multirow{2}{*}{$\begin{array}{l}\text { No. of } \\
\text { patients }\end{array}$} & \multirow[b]{2}{*}{ Clinical status } & \multirow{2}{*}{$\begin{array}{l}\text { No. of DNA } \\
\text { specimens } \\
\text { analyzed }\end{array}$} & \multicolumn{4}{|c|}{ No. of specimens positive for CMV IE gene sequences } & \multirow{2}{*}{$\begin{array}{l}\text { Overall incidence } \\
\text { of CMV DNA } \\
\text { positivity* }\end{array}$} \\
\hline & & & Urine & Saliva & Blood & Lung & \\
\hline \multicolumn{8}{|c|}{ Group A: seropositive, culture-positive BMT patients } \\
\hline 2 & Symptomatic with IP & 46 & $\frac{17}{21}(81 \%)$ & $\frac{6}{7}(85 \%)$ & $\frac{7}{12}(58 \%)$ & $\frac{6}{6}(100 \%)$ & $78 \%$ \\
\hline 1 & Symptomatic with fever & 14 & $\frac{4}{5}(80 \%)$ & $\frac{5}{5}(100 \%)$ & $\frac{0}{4}(0 \%)$ & - & $64 \%$ \\
\hline \multicolumn{8}{|c|}{ Group B: Seropositive, culture-negative BMT patients } \\
\hline 1 & Asymptomatic with seroconversion & 29 & $\frac{4}{11}(36 \%)$ & $\frac{2}{7}(28 \%)$ & $\frac{3}{11}(27 \%)$ & - & $31 \%$ \\
\hline 1 & Asymptomatic & 24 & $\frac{0}{7}(0 \%)$ & $\frac{0}{7}(0 \%)$ & $\frac{0}{10}(0 \%)$ & - & $0 \%$ \\
\hline \multicolumn{8}{|c|}{ Group C: Seronegative, culture-negative BMT patients } \\
\hline 3 & Asymptomatic & 41 & $\frac{0}{12}(0 \%)$ & $\frac{0}{13}(0 \%)$ & $\frac{0}{16}(0 \%)$ & - & $0 \%$ \\
\hline \multicolumn{8}{|c|}{ Group D: Seropositive, culture-negative blood donors } \\
\hline 3 & Asymptomatic & 65 & $\frac{0}{11}(0 \%)$ & $\frac{3}{11}(27 \%)$ & $\frac{2}{43}(4.7 \%)^{\ddagger}$ & - & $7.7 \%$ \\
\hline \multicolumn{8}{|c|}{ Group E: Seronegative, culture-negative blood donors } \\
\hline 13 & Asymptomatic & 285 & $\frac{2}{77}(2.6 \%)^{\S}$ & $\frac{2}{80}(2.5 \%)^{\S}$ & $\frac{0}{128}(0 \%)$ & - & $1.4 \%$ \\
\hline
\end{tabular}

* This table shows the overall results of CMV testing at multiple time points (i.e., results have not been related to time sequences in CMV infections). ${ }^{\ddagger}$ The two positive peripheral blood specimens in group D were taken from a single CMV-seropositive donor. ${ }^{\S}$ All four positive specimens in group $\mathrm{E}$ (two urine, two saliva) came from one seronegative donor.

and cyclosporin. A rectal biopsy at week 7 was suggestive of CMV infection and by week 8 the patient had developed IP. Bronchial washings, urine, sputum, and blood specimens at this time were CMV culture negative and CMV DNA hybridization positive (Fig. $3 \mathrm{~A}$; lanes 2-5) with bronchial washings showing the strongest hybridization signals. In blood, CMV was concentrated in the PMN cell fraction. By week 9, the patient became CMV IgM antibody positive and was diagnosed clinically as having CMV IP. She was treated with acyclovir and beta IFN and her condition improved. Repeat bronchial washings at week 12 were both culture and hybridization positive. Urine and blood specimens at this time were CMV culture negative and CMV DNA positive. A transbronchial biopsy showed one cell with an intranuclear inclusion body, a pathologic feature suggestive of $\mathrm{CMV}$ infection. The patient recovered and remained CMV IgM and IgG antibody positive. CMV viremia, as determined by the PCR method, continued for $48 \mathrm{wk}$ and then disappeared precipitously. Excretion of CMV DNA in urine and throat was sustained at high levels throughout the 60-wk study period.

Patient 2 was a 35-yr-old man with acute lymphoblastic leukemia in second remission. He received an HLA-compatible BMT from a male sibling in May 1986. Both donor and recipient were CMV IgG antibody positive (IgM antibody negative) pretransplant. Peripheral blood of the patient was CMV DNA negative (culture negative). Urine and saliva were weakly positive by DNA and negative by culture. At 4 wk posttransplant the patient developed episodic fever and CMV was cultured from urine. This correlated with a significant increase of CMV DNA excretion in saliva, which was sustained throughout the study period. The patient recovered and remained CMV seropositive. CMV DNA was not detected in this patient's blood (data not shown).

Patient 3 (Fig. 3 B lanes 5-7; Fig. 5) was an 18-yr-old woman with severe aplastic anemia. She received a BMT in December 1985 from an HLA-DR matched female sibling. Both donor and recipient were CMV IgG/IgM and CMV DNA negative pretransplant. The patient's posttransplant course was unremarkable. At week 11 CMV DNA appeared in her peripheral blood and by week 17 she had seroconverted to CMV IgM antibody positivity. At week 17 CMV DNA was also found in urine. This patient remained asymptomatic and CMV culture negative. CMV DNA was cleared from the peripheral blood by week 28 (Fig. 5).

The fourth patient (Fig. $3 \mathrm{~B}$, lanes $1-4$ ) was a 31-yr-old female with chronic myelogenous leukemia in chronic phase who received a sibling BMT in September 1985. Donor and recipient were CMV IgG antibody positive pretransplant. An esophageal biopsy at $6 \mathrm{wk}$ showed nuclear inclusions suggestive of CMV. Pneumonitis was clinically apparent at $6 \frac{1}{2} \mathbf{w k}$. Open lung biopsy $3 \mathrm{~d}$ later revealed mild nonspecific IP with no inclusion bodies. The biopsy was CMV culture and DNA positive. Urine and peripheral blood were hybridization positive. Despite therapy, this patient died of CMV IP at $10 \mathrm{wk}$ post-BMT.

Patterns of CMV reactivity in individual blood donors. All three CMV seropositive donors were IgG positive, IgM negative. The IgG antibody patterns were remarkably stable, show- 

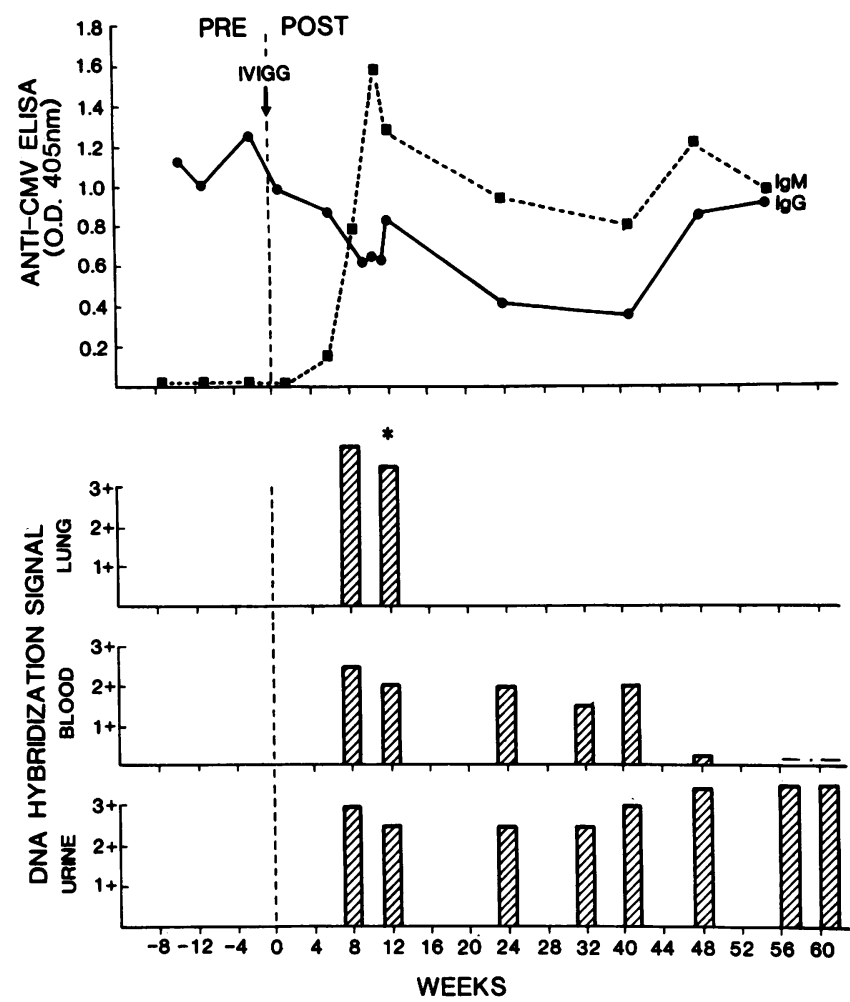

Figure 4. Patterns of CMV antibody and CMV DNA reactivity in BMT patient 1 over time. Fluctuating levels of $\mathrm{IgG}$ antibody to CMV were observed before (PRE) and after (POST) transplant. At least part of this fluctuation was due to CMV immunoprophylaxis (IVIGG, Sandoglobin) which was given daily for $3 \mathrm{~d}$ pretransplant and once weekly posttransplant (arrow). IgM antibodies (OD > 0.2) were first detected $8 \mathrm{wk}$ posttransplant. At this time, high levels of CMV DNA were detectable in urine, saliva (not shown), and peripheral and bronchial washes. Bronchial washes were culture negative at 8 wk and culture positive (*) at $12 \mathrm{wk}$. CMV viremia, as detected by PCR analysis, continued for $41 \mathrm{wk}$ and then disappeared precipitously. Excretion of CMV DNA in urine was sustained at high levels throughout the study period.

ing little or no variation in titer over $18 \mathrm{mo}$. DNA patterns, on the other hand, were fluctuating in nature showing intermittent excretion of CMV DNA in urine and saliva and intermittent CMV DNA viremia. Retesting of donor specimens gave the same result.

Overall comparison of DNA hybridization and viral culture. A total of 512 clinical specimens (including the 8 non-BMT urine isolates) were analyzed by both PCR and culture methods. Hybridization and culture yielded concordant results with 456 samples; 441 samples were negative and 15 samples were positive with both test systems. The remaining 56 specimens were DNA hybridization positive but culture negative. 47 of these discrepant samples came from BMT patients with confirmed CMV infection; 5 came from $2 \mathrm{CMV}$ seropositive blood donors, and 4 samples ( 2 urine and 2 saliva) were taken from a single CMV seronegative blood donor.

\section{Discussion}

Rapid diagnosis of CMV can be accomplished by detection of the viral genome (7-11). Most CMV DNA diagnostic assays have involved DNA extraction and dot blot hybridization

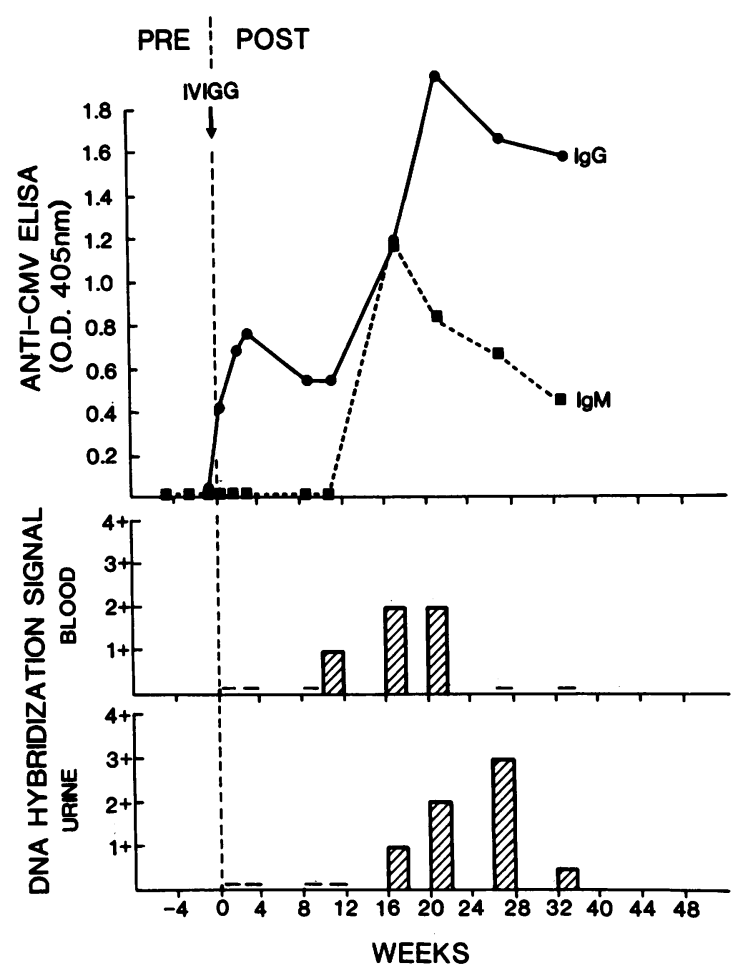

Figure 5. Patterns of CMV antibody and CMV DNA reactivity in BMT patient 3 over time. Patient 3 was CMV negative pretransplant $(P R E)$. CMV IgG seropositivity was first detected near the time of transplant and presumably reflects the passive acquisition of antibody due to immunoprophylaxis (arrow). At 11 wk posttransplant (POST) CMV DNA was detected in peripheral blood and by week 17 the patient showed seroconversion for IgM antibodies to CMV. CMV DNA was excreted in urine beginning at week 17 . This patient remained asymptomatic and CMV DNA was cleared from blood by 28 wk. Low levels of CMV DNA were still detectable in urine at 33 wk posttranisplant.

using recombinant fragments of $\mathrm{CMV}$ as probes. These assays have a sensitivity limit of only 1 viral genome per 20 cells (31). In addition to low sensitivity, conventional dot blot assays are limited by problems inherent in the methodology. Contaminants in the DNA extract can interfere with DNA binding to filters resulting in reduced specific adherence and false negative results. Alternatively, contaminants can result in nonspecific probe trapping and the detection of false positives (12). Bacteria in clinical specimens can also lead to false positive reactions $(11,12)$. This problem, the vector homology problem, arises when vector sequences in the recombinant probe hybridize to homologous sequences contained in bacteria of the test specimen. The use of extensively purified viral insert probes and control hybridization with vector DNA is only partially effective in eliminating this problem $(9,13)$.

To overcome these problems we have used PCR amplification in combination with oligonucleotide probe hybridization. As in recent studies with $\operatorname{HIV}-\mathrm{I}(18,19)$ and human T cell lymphoma/leukemia virus (20), the amplification step results in a significant increase in the sensitivity of viral DNA detection. In addition, it permits the electrophoretic separation and accurate identification of the amplified viral sequence, even in crude preparations containing large amounts of cellular debris. The use of synthetic oligonucleotide probes eliminates the 
vector homology problem associated with recombinant DNA technology.

In preliminary testing we have shown that PCR can reproducibily detect one copy of the CMV IE target sequence in 40,000 cells. This corresponds to a 2,000-fold increase in sensitivity over unamplified DNA assays for the detection of CMV IE sequences $(11,31)$. The successful amplification of Davis and AD169 strains, as well as eight of eight wild-type strains of CMV, indicates that the PCR assay recognizes most, if not all, CMV strains. The ability to identify a wide range of strains was expected since amplification sequences were selected from a highly invariant region of the CMV genome. These sequences are known to be identical in both Towne and AD169 strains $(24,25)$. The high specificity of the PCR assay was shown by the complete lack of hybridization with human cellular DNA, $E$. coli DNA, or DNA from other herpes viruses.

The clinical applicability of the CMV PCR test has been shown in a longitudinal surveillance study of CMV infection in BMT patients. The PCR assay correctly identified four patients with documented CMV infection. Three of these patients were followed longitudinally. In these patients, the appearance of CMV DNA preceded clinical and/or serological evidence of CMV infection. These results suggest that PCR is a valuable marker for the early stages of CMV infection. Since this work was completed, Loche and Mach (32) have reported similar results for HIV. Using PCR methods, they detected HIV DNA in 5 of 16 high-risk seronegative sexual partners of HIV seropositive persons. They concluded that PCR technology was capable of identifying infected individuals before the development of antibody. Clinical and serological follow-up of these patients, however, has not yet been completed.

The ability of PCR to identify CMV in the peripheral blood of BMT patients is particularly important since CMV viremia is frequently associated with serious disease (33). In this study, CMV DNA was identified in peripheral blood of both patients who developed IP. Although the levels of CMV in blood were lower than in lung and urine, we believe this reflects differences in viral titer rather than a lack of sensitivity with blood specimens. This is based on reconstruction experiments and on studies in AIDS patients where high levels of CMV are frequently detected in peripheral blood (unpublished results). The concentration of CMV in the PMN cell fraction suggests that blood is functioning primarily to clear CMV infections.

Overall, CMV DNA was identified in seven of seven culture-positive BMT specimens. In addition, CMV DNA was identified in 47 of $147 \mathrm{CMV}$ culture-negative specimens. All of these specimens came from the four patients with confirmed infection. Since we have probed with synthetic oligonucleotides (devoid of vector contamination), it is unlikely that these results are due to nonspecific probe binding to bacteria. An alternative explanation is that some specimens may contain defective virions that do not grow in culture. However, the early detection of CMV DNA in patients who later became culture positive suggests that PCR technology can identify CMV with higher sensitivity than viral culture. Similar results have been reported for HIV. Ou and colleagues (19); using PCR methods, were able to demonstrate HIV in 11 of 11 (100\%) DNA samples from HIV culture-positive, seropositive homosexual men. They also detected HIV in 7 of $11(64 \%)$ DNA samples from high-risk seropositive, but culture-negative homosexual men, suggesting that PCR was the more sensitive technology.
Validation of our donor data is more difficult since donor infections are usually asymptomatic and CMV cannot be cultured from donor units. Previous infection can be inferred by the presence of IgG antibodies to CMV. However, it appears that only a small percentage of previously infected people enter a latent phase that remains infectious in a blood donor's product. Schrier and colleagues (34), using in situ hybridization, were able to detect CMV RNA transcripts in $0.03-2.0 \%$ of PBMC in eight of eight asymptomatic seropositive donors. Spector and associates (35), using a dot blot assay, detected CMV in the peripheral blood of 3 of 41 seropositive donors. However, we and others $(31,36)$, using similar technology, have been repeatedly unable to identify CMV DNA in blood donors. In the present study, using sensitive PCR methods, we were able to detect CMV in two of three seropositive donors and in 1 of 13 seronegative donors. Patterns of CMV DNA reactivity in individual donors over time showed only intermittent CMV viremia and excretion. This is in contrast to the protracted DNA patterns observed in the BMT population and suggests a low level of viral activity that is only periodically detectable by hybridization. The detection of CMV DNA in only 2 of $43(4.7 \%)$ of peripheral blood specimens from seropositive donors is consistent with what is known about CMV carrier rates in the donor population. These rates have been estimated to range between 1 and 13\% (37).

There are several possibilities to explain the lack of CMV DNA detection in two seropositive, culture-negative individuals (one donor and one BMT patient). One possibility is that the PCR assay is not sufficiently sensitive to detect the very low levels of virus present in these persons. This possibility could, in theory, be resolved by increasing the number of PCR amplification cycles. Alternatively, it could indicate that these individuals have been exposed to $\mathrm{CMV}$ in the past but that their infection has been successfully resolved. A third possibility is that these individuals harbor strains of CMV that are not detectable by the present PCR assay or that they carry viral genomes that are defective in the IE region. A fourth possibility is that these individuals are temporarily in an inactive (latent) phase and that continued monitoring will eventually result in the detection of positives. The detection of CMV DNA in one CMV seronegative donor is more difficult to explain. We are currently sequencing this amplification product to confirm its identity.

To summarize, our findings suggest that PCR amplification technology is more sensitive than conventional culture methods for the diagnosis of CMV. One of the major advantages of the technology is its applicability to a wide variety of biological specimens. In longitudinal surveillance studies we have shown that DNA testing of multiple tissues can provide additional information on the overall CMV status of BMT patients. It is anticipated that ongoing serial study will eventually lead to the identification of CMV reactivity patterns that are of diagnostic importance. The potential of the PCR assay to detect early CMV, especially CMV viremia, has important implications since early diagnosis may allow physicians to modify antiviral or immunosuppressive regimens in time to alter the course of serious CMV disease.

\section{Acknowledgments}

The authors would like to thank Dr. K. Buchan and Mr. T. Stowe of the clinical virology laboratory, Foothills Hospital, for providing viral culture studies. 
These studies were supported by the Canadian Red Cross, Blood Transfusion Service, grants CA-02-84 and CA-02-87.

\section{References}

1. Hirsch, M. S. 1981. Herpes group virus infections in the compromised host. In Clinical Approach to Infection in the Compromised Host. R. H. Rubin and L. S. Young, editors. Plenum Medical Book Co., New York. 389-415.

2. Drew, W. L., E. S. Mocarski, E. Sweet, and R. C. Miner. 1984. Multiple infections with CMV in AIDS patients: documentation by Southern blot hybridization. J. Infect. Dis. 150:954-960.

3. Meyers, J. D., N. Fluornoy, and E. D. Thomas. 1982. Nonbacterial pneumonia after allogeneic marrow transplantation: a review of 10 years' experience. Rev. Infect. Dis. 4:1119-1132.

4. Rasmussen, L., D. Kelsall, and R. Nelson. 1982. Virus-specific IgG and IgM antibodies in normal and immunocompromised subjects infected with cytomegalovirus. J. Infect. Dis. 145:191-199.

5. Starr, S. E., and H. M. Friedman. 1980. Human cytomegalovirus. In E. H. Lenette, A. Balows, W. J. Hausler, and J. P. Truant, editors. Manual of Clinical Microbiology. 3rd ed. American Society for Microbiology, Washington, DC. 790-797.

6. Emanuel, D., J. Peppard, D. Stover, J. Gold, D. Armstrong, and U. Hammerling. 1986. Rapid immunodiagnosis of cytomegalovirus pneumonia by bronchoalveolar lavage using human and murine monoclonal antibodies. Ann. Intern. Med. 104:476-481.

7. Chou, S., and T. C. Merigan. 1983. Rapid detection and quantitation of human cytomegalovirus in urine through DNA hybridization. N. Engl. J. Med. 308:921-925.

8. Spector, S. A., and D. H. Spector. 1985. The use of DNA probes in studies of human cytomegalovirus. Clin. Chem. 31:1514-1520.

9. Kahan, B. D., and T. A. Landers. 1985. Rapid detection of cytomegalovirus infection using a DNA probe. Transplant. Proc. 17:989-993.

10. Virtanen, M., A.-C. Syvanen, J. Oram, H. Soderlund, and M. Ranki. 1984. Cytomegalovirus in urine: detection of viral DNA by sandwich hybridization. J. Clin. Microbiol. 20:1083-1088.

11. Augustin, S., T. Popow-Kraupp, F. X. Heinz, and C. Kunz. 1987. Problems in detection of cytomegalovirus in urine samples by dot blot hybridization. J. Clin. Microbiol. 25:1973-1977.

12. Ambinder, R. F., P. Charache, S. Staal, P. Wright, M. Forman, S. D. Hayward, and G. S. Hayward. 1986. The vector homology problem in diagnostic nucleic acid hybridization of clinical specimens. $J$. Clin. Microbiol. 24:15-20.

13. Schister, V., B. Matz, H. Wiegand, B. Traub, D. Kampa, and D. Neumann-Hafelin. 1986. Detection of human cytomegalovirus in urine specimens by DNA-DNA and RNA-DNA hybridization. $J$. Infect. Dis. 154:309-314.

14. Saiki, R. K., S. Shark, F. Faloona, K. B. Mullis, G. T. Horn, H. A. Erlich, and N. Arnheim. 1985. Enzymatic amplification of betaglobin genomic sequences and restriction site analysis for diagnosis of sickle cell anemia. Science (Wash. DC). 230:1350-1354.

15. Embury, S. H., S. J. Scharf, R. K. Saiki, M. A. Gholson, M. Golbus, N. Arnheim, and H. A. Erlich. 1987. Rapid prenatal diagnosis of sickle cell anemia by a new method of DNA analysis. $N$. Engl. $J$. Med. 316:656-661.

16. Kogan, S. C., M. Doherty, and J. Gitschier. 1987. An improved method for prenatal diagnosis of genetic diseases by analysis of amplified DNA sequences. $N$. Engl. J. Med. 317:985-990.

17. Shibata, D. K., N. Arnheim, and W. J. Martin. 1988. Detection of human papilloma virus in paraffin-embedded tissue using the polymerase chain reaction. J. Exp. Med. 167:225-230.

18. Kwok, S., D. H. Mack, K. B. Mullis, B. Poiesz, G. Ehrlich, D. Blair, A. Friedman-Kien, and J. J. Sninsky. 1987. Identification of human immunodeficiency virus sequences by using in vitro enzymatic amplification and oligomer cleavage detection. J. Virol. 61:16901694.

19. Ou, C.-Y., S. Kwok, S. W. Mitchell, D. H. Mack, J. J. Sninsky, J. W. Krebs, P. Feorino, D. Warfield, and G. Schochetman. 1988. DNA amplification for direct detection of HIV-1 in DNA of peripheral blood mononuclear cells. Science (Wash. DC). 239:295-297.

20. Duggan, D. B., G. D. Ehrlich, F. P. Davey, S. Kwok, J. Sninsky, J. Goldberg, L. Baltrucki, and B. J. Poiesz. 1988. HTLV-1 induced lymphoma mimicking Hodgkin's disease, diagnosis by polymerase chain reaction amplification of specific HTLV-1 sequences in tumor DNA. Blood. 71:1027-1032.

21. Fleckenstein, B., I. Muller, and J. Collins. 1982. Cloning the complete human cytomegalovirus genome in cosmids. Gene. 38:3946.

22. Hoar, D. I., D. B. Haslam, and D. M. Starozik. 1984. Improved direct molecular diagnosis and rapid fetal sexing. Prenatal Diagn. 2:241-247.

23. Hoar, D. I., T. Bowen, D. Matheson, and M. C. Poon. 1985. Hepatitis B virus DNA is enriched in polymorphonuclear leukocytes. Blood. 66:1251-1253.

24. Akrigg, A., G. W. G. Wilkinson, and J. D. Oram. 1985. The structure of the major immediate early gene of human cytomegalovirus strain AD169. Virus Res. 2:107-121.

25. Pritchett, R. F. 1980. DNA nucleotide sequence heterogeneity between the Towne and AD169 strains of cytomegalovirus. J. Virol. 36:152-161.

26. Rudiger, R., G. W. Bornkamm, and B. Fleckenstein. 1984. Human cytomegalovirus DNA sequences with homologies to the cellular genome. J. Gen. Virol. 65:1351-1364.

27. Peden, K., P. Mounts, and G. S. Hayward. 1982. Homology between mammalian cell DNA sequences and human herpesvirus genomes detected by a hybridization procedure with high complexity probe. Cell. 31:71-80.

28. Beaucage, S. L., and M. H. Caruthers. 1981. Deoxynucleoside phosphoramidites: a new class of key intermediates for deoxypolynucleotide synthesis. Tetrahedron Lett. 22:1859-1862.

29. Southern, E. M. 1975. Detection of specific sequences among DNA fragments separated by gel electrophoresis. J. Mol. Biol. 98:503-517.

30. Maniatis, T., Fritsch, E. F., and J. Sambrook. 1982. Molecular Cloning Manual. Cold Spring Harbor Laboratory, Cold Spring Harbor, New York. 122-123.

31. Jackson, J. B., H. T. Orr, J. J. McCullough, and M. C. Jordan. 1987. Failure to detect human cytomegalovirus DNA in IgM-seropositive blood donors by spot hybridization. J. Infect. Dis. 156:10131016.

32. Loche, M., and B. Mach. 1988. Identification of HIV-infected seronegative individuals by a direct diagnostic test based on hybridisation to amplified viral DNA. Lancet. ii:418-421.

33. Saltzman, R. L., M. R. Quirk, and M. C. Jordan. 1988. Disseminated cytomegalovirus infection. Molecular analysis of virus and leukocyte interaction in viremia. J. Clin. Invest. 81:75-81.

34. Schrier, R. D., J. A. Nelson, and M. B. A. Oldstone. 1985. Detection of human cytomegalovirus in peripheral blood lymphocytes in a natural infection. Science (Wash. DC). 230:1048-1051.

35. Spector, S. A., J. A. Rua, D. H. Spector, and R. McMillan. 1984. Detection of human cytomegalovirus in clinical specimens by DNA-DNA hybridization. J. Infect. Dis. 150:121-126.

36. Cassol, S., D. Hoar, E. Wong, K. Buchan, and C. Snider. 1985. Detection of cytomegalovirus DNA in clinical specimens using DNA dot hybridization. Blood. 66:258a. (Abstr.)

37. Tegtmeier, G. E. 1985. Cytomegalovirus and blood transfusion. In Infection, Immunity and Blood Transfusion. Alan R. Liss, Inc., New York. 175-199. 